\title{
Renewable Energy Sources: Global and Russian Outlook Up to 2040
}

\author{
Anna Galkina, Vyacheslav Kulagin and Irina Mironova*
}

\author{
Energy Research Institute of the Russian Academy of Sciences, 31/2 Nagornaya St., 117186 Moscow, \\ Russia
}

\begin{abstract}
During the period up to 2040, renewable energy sources (RES) will have the highest growth rates of all forms of energy. Based on the calculations on the world energy model incorporated in the SCANER modelling and information complex (working on the basis of optimization, econometric analysis, and balance approach), key trends in the world consumption of renewable energy sources; the share of OECD and non-OECD countries in the use of the renewable energy sources; consumption of renewable energy sources by type; end use and the impact on the electricity sector during the period up to 2040 were observed. The main finding of the paper is that RES are becoming more competitive and therefore will be used on an increasingly wide scale not only in the OECD countries, but also in the whole world. At the same time, due to the fact that RES start their take-off from a modest basis, they will only have a limited influence on the shares of hydrocarbons in the energy mix.
\end{abstract}

Keywords: Renewable energy sources, energy system, energy markets, optimization model, balance approach.

\section{INTRODUCTION}

The use of renewable energy sources (RES) ${ }^{1}$ has been growing significantly over the past years due to a number of benefits which lie in various dimensions. First of all, from the perspective of energy security, renewable energy sources can provide with opportunities of the fuel mix diversification, which is most relevant for the economies which are dependent on imports of fossil fuels. Secondly, with increased use of renewable sources economies can decrease their environmental impact (decrease $\mathrm{CO} 2$ emissions per unit of GDP and also decrease air pollution). Thirdly, there could be economic considerations behind more active use of RES. As noted by the IEA, "the development and deployment of renewables can form part of comprehensive strategies aimed at more sustainable economic growth (often called 'green growth'). Renewable energy has featured strongly in economic recovery packages put in place in response to the global economic downturn" [1]. Fourthly, it is renewable energy sources, which can be one of the most effective tools in solving the problem of energy access.

These reasons have led to specific policies being introduced in order to promote the development and

*Address correspondence to this author at the Energy Research Institute of the Russian Academy of Sciences, 31/2 Nagornaya St., 117186 Moscow, Russia; Tel: 007 (499) 123 0501; Fax: 007 (499) 123 4485;

E-mail: irina.mironova.usu@gmail.com

${ }^{1}$ Within this study renewable energy sources include biofuels (bioethanol, biodiesel, biogas, landfill gas, wood pellets, other solid and liquid biofuels), hydro, waste, solar, wind, tidal, geothermal, wave, ocean. deployment of renewable energy sources in different regions of the world. Renewables already have made a significant impact on energy systems, and are projected to continue their growth within the energy mix and making an impact on energy system, energy trade and energy security.

RES are very diverse in nature and are used in various fuel markets: biogas competes in the market of gas fuel, while bioethanol and biodiesel do the same in the liquid fuel market, wood and wood pellets in the solid fuel market, solar and wind energy-in the electricity market. Particularly because of these factors, changes in the RES sector have a potential to influence various sectors of energy systems and the fuel mix.

The purpose of this paper is to analyse the prospective of the changes related to the renewable energy sources based on the forecast of the sector development. The basis for the analysis is provided by the modelling tool of the world and Russian energy sector in the period up to 2040 [2], which serves as the basis for projections within the Russian and Global Energy Outlook Up to 2040. Within the Outlook, analysis of the renewables sector perspectives is only one of the tasks. The ultimate value of the Outlook is a much more detailed analysis of the Russian energy sector and its interconnections with international energy markets; therefore, the current paper focuses only on a small segment of the overall findings acquired through the modelling of world energy system development in the period up to 2040. It is important nevertheless to see the perspectives of RES sector within this larger picture, because it explains the nature of the challenges faced by Russia in international 
markets, as well as the changes that have to be dealt with by traditional fossil fuel industries.

The paper is structured in the following way: In the Methodology section, the overview of the SCANER modelling complex is provided. With the use of the modelling complex, the projections are built both in the global perspective as well as specifically for Russia. The next section outlines the Baseline scenario of the Russian and Global Energy Outlook Up to 2040 [2]. The outcomes of the modelling specific for the RES segment are looked at in detail thereafter. The key findings are presented in the conclusions section and include the following observations:

- renewable energy sources are becoming more competitive and therefore will be used on an increasingly wide scale;

- $\quad$ this dynamics will not be exclusive for the OECD countries, but will have a worldwide effect;

- $\quad$ at the same time, due to the fact that renewable energy sources start their take-off from a modest basis, they will only have a limited influence on the shares of hydrocarbons in the energy mix.

Overall, these findings do not contradict the RES sector outlook within other energy system development outlooks, namely IEA's World Energy Outlook [1], Annual Energy Outlook of the Energy Information Administration [3], BP [4], ExxonMobil [5] (see Figure 1). All of the forecasts show the increase in use of RES. The largest difference between minimum and maximum level of RES deployment is found in the IEA outlook; this can be explained by the wide variance in policies between the scenarios. ERIRAS forecast falls within the range identified by the IEA, is higher than forecasts for RES of BP and ExxonMobil, and close to the maximum range within the Annual Energy Outlook of the EIA.

\section{METHODOLOGY}

The current analysis is based upon the calculation received with the set of models, which is incorporated in the SCANER modelling and information complex. The core elements of the approach are optimization, econometric analysis, and balance approach.

The SCANER complex [6] consists of several simulation and optimization modules; there are also information systems such as databases and expert analytical tools linked to the modules. SCANER uses matrix structure (four-level industry and three-level geographical). The modelling modules include: module for the development of scenarios of external conditions; module for global energy forecasts; module for forecasting the socio-economic development of Russia and its regions; module for forecasting energy consumption and development of fuel and energy balances; electric power sector module; oil and oil refining industry module; gas industry module; coal industry module. Interaction between information and modelling modules is organised within an interactive set up; energy demand of the economy and production and financial capabilities of the industries in the energy sector, as well as energy companies, are therefore coordinated within the complex.

World energy markets prospects are analysed using the module for global energy. It is the set of models that contains world primary energy demand module, balance module, world gas, oil, coal, renewables and nuclear models and power generation module. The basis of the retrospective information on the majority of world energy indicators is International Energy Agency (IEA) data.

Firstly, the demand for primary energy, electricity, and liquid fuels (oil products, etc.) for more than 80 countries is calculated using: 1) forecasted indicators of GDP, population and 2) forecasts for energy intensity, electricity intensity, oil intensity of GDP and, correspondingly, per capita energy, electricity and oil consumption. Forecasts for intensity of GDP and per capita indicators are based on linear trends:

$$
Y(t)=a+b^{*} t,
$$

where $t$ is the time index. Indicators of intensity of GDP are then multiplied by GDP and per capita consumption indicators are multiplied by population. The outcome of this calculation are two ranges of energy, electricity and oil forecasted consumption. The resulting demand for primary energy, liquid fuels and electrical power is derived when such trends in two ranges, the difference between which is minimal, are found.

Next stage is the balance module, where the demand for oil, renewables and nuclear energy (calculated in renewables and nuclear modules) is subtracted from the primary energy demand. Since the resource modules, particularly, world gas model, are large-scale, a separate optimizator is used for calculations. Production volumes, trade flows, gas prices as well as optimized demand side responses reflecting interfuel competition can be derived from a 


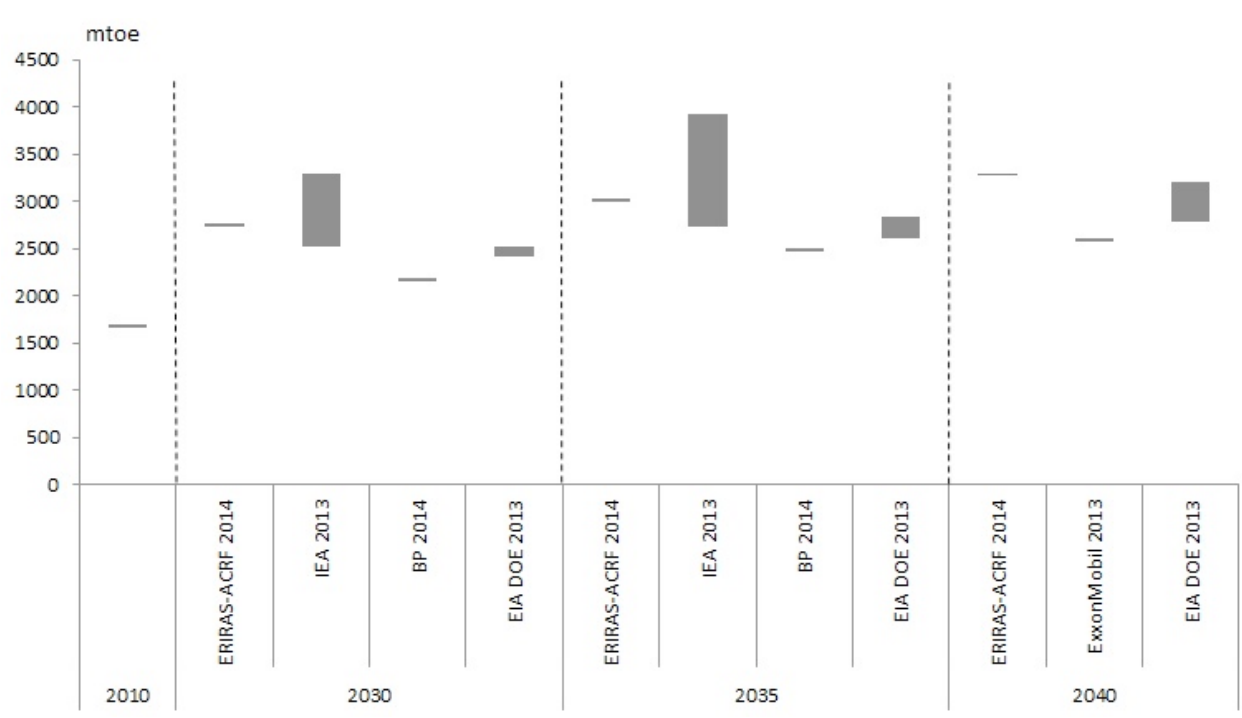

Figure 1: Comparison of various outlooks for RES, ranges between minimum and maximum use, mtoe.

Sources: [1], [2], [3], [4], [5]

model. The remaining demand is then distributed between coal and natural gas taking into account conditions of interfuel competition:

\section{DSRtotal $=\sum$ (Aprice $1{ }^{*} D S R$ volume $1+$ Bprice2 ${ }^{*} D S R$ volume2 + Cprice ${ }^{*}$ DSRvolume3),}

where: DSRtotal - Overall demand side response;

DSRvolume1,2,3 - Maximum possible volume of DSR switch for each of the 3 thresholds in the node;

Aprice1 - a coefficient received as a result of optimization reflecting how much gas available for threshold 1 of the node is not used at price 1 and thus demand is switched to RES; measured on the scale from 0 to 1 ;

Bprice2 - a coefficient received as a result of optimization reflecting how much gas available for threshold 2 of the node is not used at price 2 and thus demand is switched to RES; measured on the scale from 0 to 1 ;

Cprice3 - a coefficient received as a result of optimization reflecting how much gas available for stage 3 of the node is not used at price 3 and thus the demand is switched to RES; measured on the scale from 0 to 1 .

Demand for coal and natural gas = Demand for primary energy - Oil demand - Demand for renewables - Demand for nuclear energy.

After that forecasts of demand for oil, natural gas and coal are transferred to world oil, gas and coal optimization models (resource modules). The calculation base in these models contains up to 200 nodes across the world. The main objective of all resource modules is to find solutions to the optimization objective (which is to minimise the total costs of meeting energy demand, while taking into account the economic feasibility of fuel substitutions). The outputs from these models are forecasts of production volumes, trade flows and prices for oil, gas and coal. After running all resource modules, the demand for each fuel is adjusted taking into account price ratios between them and the availability of supply.

Renewable and nuclear modules are not developed as optimization model since the determining factors are of non-economic nature. Forecast of nuclear energy consumption is calculated based on data on all existing, constructed and planned nuclear units all over the world and country analyses of nuclear energy policies and plans. Forecast of renewables consumption is based on analyses of existing and planned RES capacities and national targets for renewables markets development. Another part of demand for renewables is a demand side response from world gas model - when some price thresholds are reached, it becomes more economically efficient to meet some volumes of demand with renewables. The volumes and price thresholds are dynamic and differ from country to country. The resulting figures on forecasted renewables and nuclear energy consumption are calculated as follows:

Forecasted demand for renewables (nuclear energy $)=$ Bases on linear trend forecasted demand for 
renewables (nuclear energy) \pm Adjustments accounting for country's energy policy + Demand side response from world gas model (the demand which has to be met by renewables rather than gas due to economic efficiency)

The results from all global energy models (e.g. possibilities of oil, gas and coal exports from Russia) are then transferred to thoroughly detailed models for assessment of the risks and prospects of the Russian energy sector; in this way world forecast is linked with a prognosis for the Russian fuel and energy complex.

At the electric power generation module, the data set is compounded with forecast of power generation by fuel types based on time series analysis of countries' fuel mixes in power generation sector, prices for fuels, efficiency of fuels combustion in the relevant nodes.

The outcomes are presented within an annual publication - Global and Russian Energy Outlook [2], which inter alia contains chapters on the perspectives of the renewable energy sources both on a global scale and with a focus on Russia. Notably, due to the fact that renewable energy sources' development depends largely on the existing energy policies, it is calculated in a separate module, which includes the structure of existing, under construction, and planned capacities, and assumptions for economic efficiency and energy policies in the individual countries.

\section{Baseline Scenario within the Global and Russian Energy Outlook Up to 2040}

The Baseline scenario of the 2014 edition of the Global and Russian Energy Outlook is based on the IMF economic growth forecasts up to 2018 [7] and own GDP projections for the rest of the forecasting period (3.5\% annually in 2010-2040) and the UN projections of the population growth $(0.9 \%$ annually to 9 billion by 2040) [8].

The main assumptions in Outlook are provided in Table 1. The established natural course of scientific and technical progress provides for the introduction of new technologies as they gradually become less expensive, and also maintains the established downward trend in the GDP energy intensity of both countries and regions, with a tendency for them to converge by the end of the forecast period. The absence of any significant technological revolutions or breakthroughs has been assumed.

According to the Baseline scenario, energy demand shifts to the non-OECD countries, which by 2040 will account for $65 \%$ or world GDP and $69 \%$ of world energy demand. OECD countries, which actively implement energy saving technologies, will increase their aggregate energy demand by only $4.6 \%$, and the bulk of this growth will happen during the period up to 2030, with stabilisation of demand thereafter. Europe and OECD Asia will even see a decrease in energy demand.

The demand for different types of fuel and electricity was received by coordinating the figures for electricity, gas, petroleum products, coal intensity of GDP, and primary energy consumption. Calculations show that demand in the period from 2010 to 2040 will grow for all forms of energy: oil by $19 \%$, coal by $36 \%$ (mainly in the period to 2020 ), gas by $64 \%$, nuclear energy by $72 \%$, and renewable energy sources by impressive 93\% (Figure 2).

Specific assumptions for the renewables sector include lower unit costs based on improvements in technology (this will have even greater impact together with the rising costs of traditional energy resources,

Table 1: Assumptions in the Baseline Scenario

\begin{tabular}{|c|c|}
\hline Topic & Assumptions \\
\hline Technologies & $\begin{array}{l}\text { 1) Technologies that are already in use at present or those that have been officially approved. } \\
\text { 2) Gradually increasing competitiveness of new technologies and the continuation of the existing trend for reduction } \\
\text { of GDP energy intensity. }\end{array}$ \\
\hline Energy Policy & $\begin{array}{l}\text { 1) Continuation of existing priorities in national energy policies and gradual introduction of plans and programmes } \\
\text { that had already been announced at the end of } 2013 \text {. } \\
\text { 2) Additional measures by energy-importing countries to improve energy security. }\end{array}$ \\
\hline Demographics & Global population will increase by almost 2 billion, to over 9 billion by 2040 (average annual growth rate of $0.9 \%$ ). \\
\hline GDP & $\begin{array}{l}\text { Global GDP will grow at an average annual rate of } 3.5 \% \text {; by } 2040 \text {, it will have increased } 2.8 \text { times compared to the } \\
\text { level in } 2010 .\end{array}$ \\
\hline
\end{tabular}

Source: [2] 


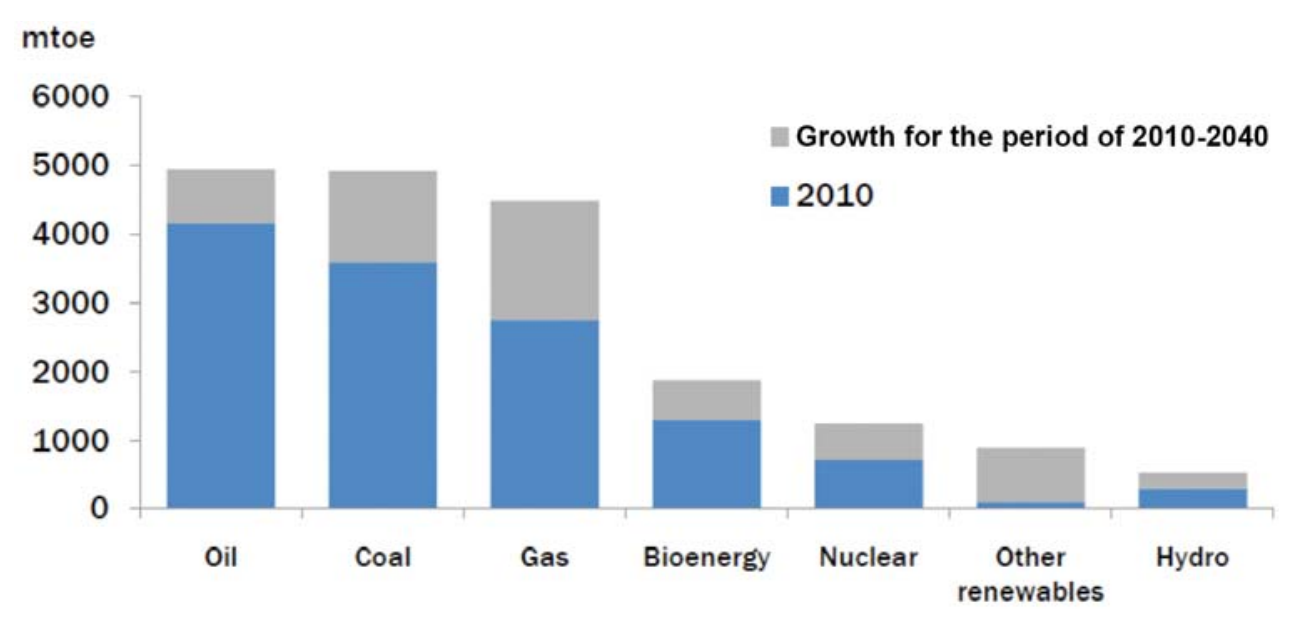

Figure 2: Primary energy demand growth by fuel, Baseline scenario.

Source: [2].

which will push up the cost of gas and coal-fired generation). As a result, all technologies enter into a fairly narrow competitive range. Moreover, OECD countries will promote non-carbon power generation. Non-OECD countries, while retaining a high dependence on coal, will rapidly increase the use renewable energy sources (as well as gas) in electricity generation.

\section{The Outlook for the Renewables}

\section{Renewables in the Energy Mix}

In the period up to 2040 , out of all energy sources, renewables will show the fastest growth rates: while energy demand during this period will increase by $47 \%$, consumption of renewable energy resources will grow by $93 \%$, achieved through the planned large-scale development of capacity based on renewable energy. However, it is the relatively low baseline values that allow for such significant growth in percentage terms: the share of renewable energy sources in the global energy mix will show a more modest increase from $13 \%$ to $17 \%$.

The growth rates of the renewables sector observed in the forecast period will be due to cheaper technology and increased competitiveness, as well as active state support. By 2040, the share of renewable energy sources (excluding hydro power, but including biofuels) will account for $14.7 \%$ of global energy consumption and $12.5 \%$ of electricity generation $(11 \%$ and $3.7 \%$ respectively in 2010).

\section{Regional Specificities}

The greatest increase in renewable energy consumption by 2040 will be in the non-OECD Asia (about $31 \%$ ), while the highest growth rates will be seen in the Middle East and the OECD Asia, largely

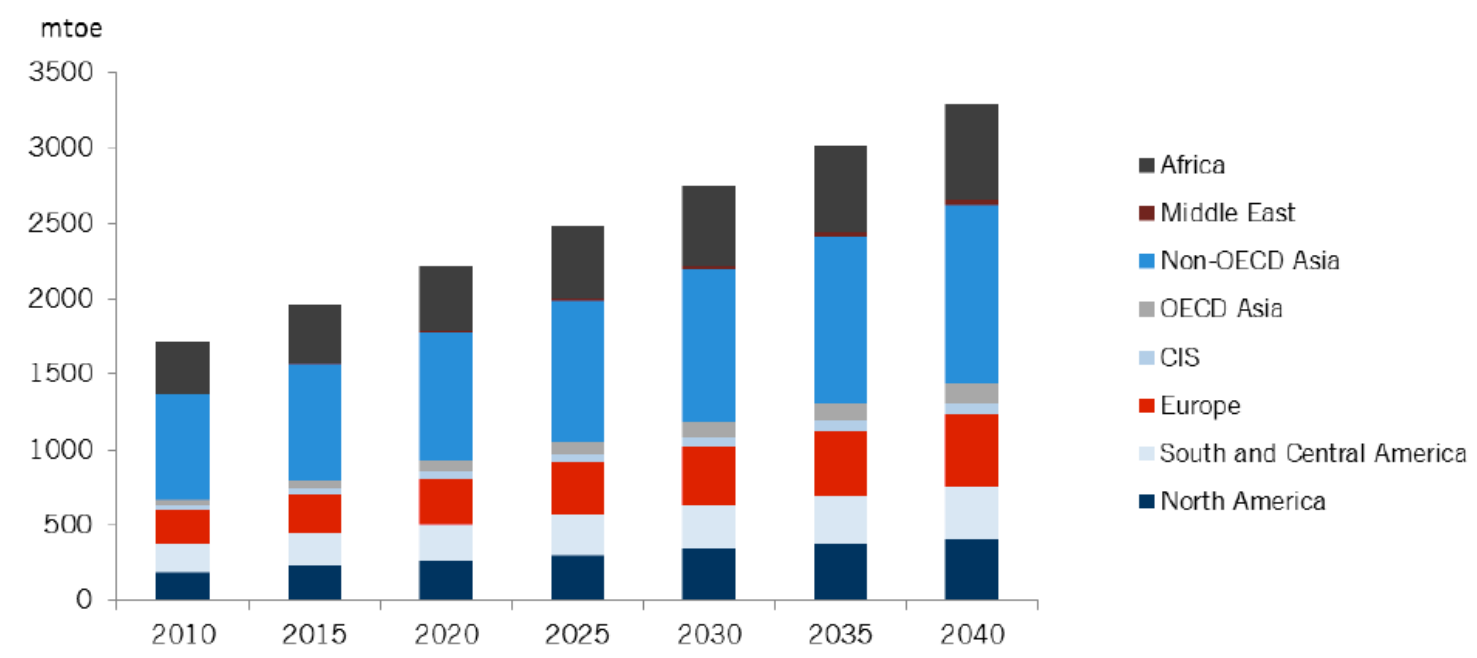

Figure 3: Forecast renewable energy sources consumption by region (2010-2040). Source: [2]. 
due to low initial figures. Of the major consumers, a more than twofold increase is forecast in Europe and North America (Figure 3).

In the period up to 2040, the consumption of renewable energy in the OECD will increase by about $130 \%$, in particular because of new renewable sources (solar, wind, etc.) which are expected to show an almost sevenfold increase (Figure 4). In developing countries, consumption of renewable energy will increase by $80 \%$, while new renewable energy sources will show an impressive (almost tenfold) increase, which will raise their share in the consumption of renewable energy to $21 \%$.

Paradoxically, for the past 40 years the major renewable energy producing regions - namely Africa, the developing countries of Asia, South and Central America - have been reducing or stabilising the proportion of renewable energy in the energy balances, rather than increasing it (Figures 3, 5). Traditionally, these regions have used solid biomass, but now its consumption is declining due to the development of other energy resources. Due to the fact that this process is closely interlinked with technological development, this trend will continue further.

\section{Changes within the Renewables Sector}

A relatively significant adjustment in the structure of renewable energy resource utilization will take place over the upcoming decades. Currently, regional consumption is dominated by solid biofuels (wood, waste, etc.) and hydropower; by 2040, wind, solar, and other forms of energy for the production of electricity and heat will come to the forefront (mainly in OECD countries) (Figure 6). It is these types of renewable energy that will show the main increase in the renewables sector of five of the eight regions under review, and they will provide nearly $50 \%$ of the

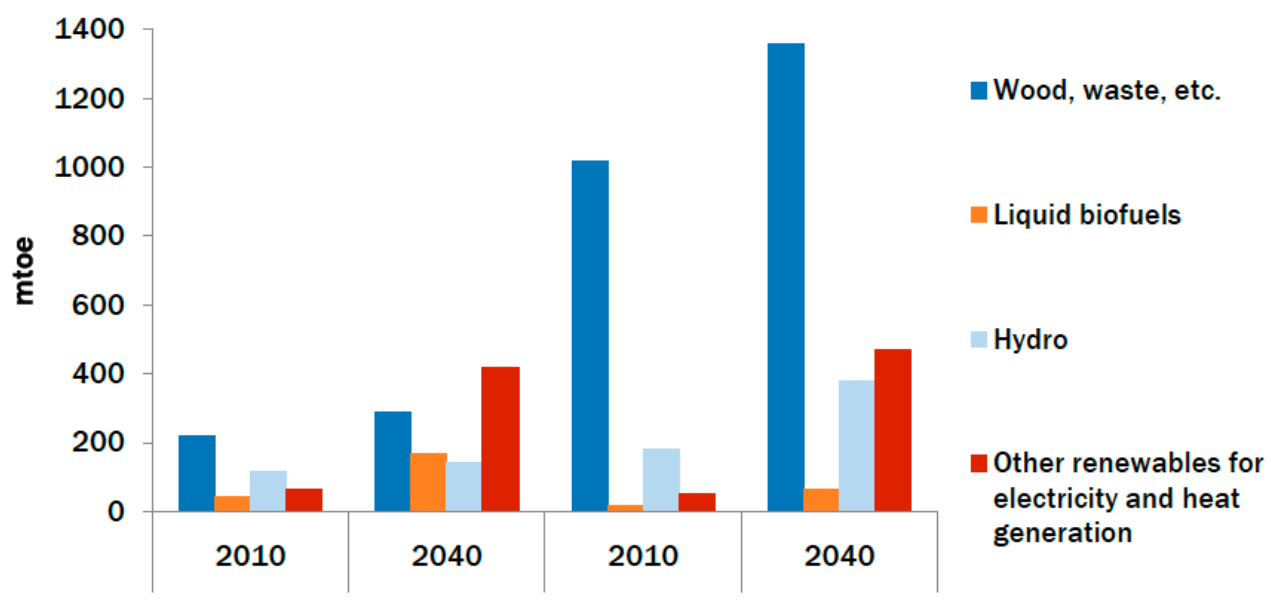

Figure 4: Renewable energy sources' consumption by type, OECD and non-OECD. Source: [2].

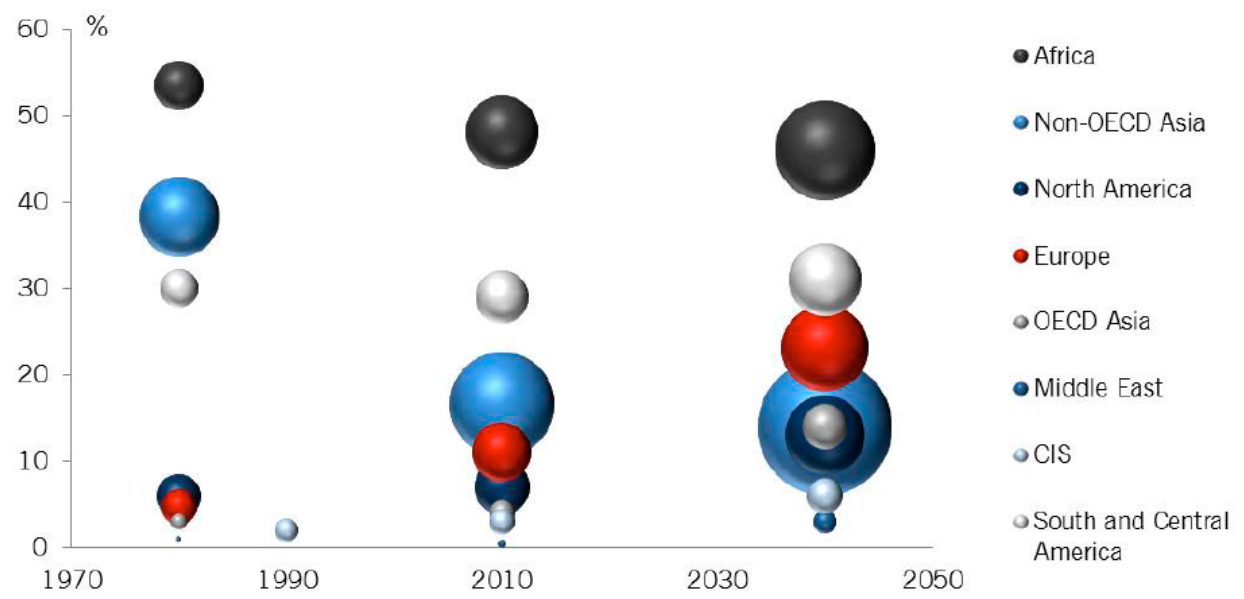

Figure 5: Share of renewable energy sources in regions' energy mix (y axis) and consumption volume (size of the circle). Source: [2]. 


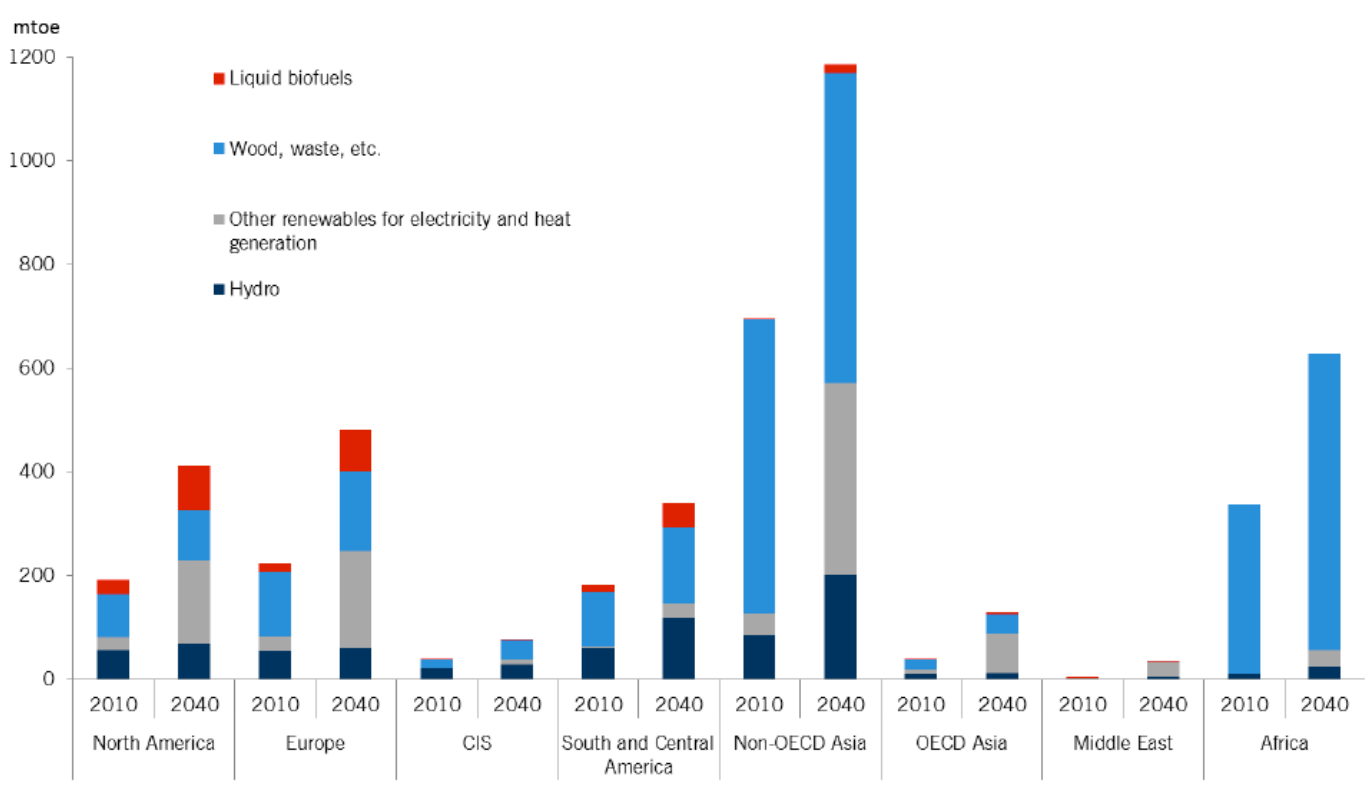

Figure 6: Dominant types of renewable energy sources by region and consumption growth. Source: [2].

increase in total renewable energy consumption worldwide.

The prospects for growth in demand for certain types of renewable energy vary widely by region. Thus, during the forecast period to 2040 , the highest increase in demand for renewable energy sources used for electricity and heat generation will be expected in China (4.4 times), which will also hold the leadership in their world consumption. A different situation will be found in the bioenergy sector, which includes "liquid biofuels" and "biomass and waste" sub-sectors. In China, the consumption of bioenergy will grow at a moderate pace $(5 \%$ increase during the forecast period), and although most of the increase will occur in liquid biofuels consumption (74\%), the most significant share of the total biomass consumption will continue to be biomass and waste ( $96 \%$ by 2040 ).

In the US, a different dynamic is expected. $94 \%$ of the growth in bioenergy consumption will be comprised of liquid biofuels; they are also will constitute a large part $(67 \%$ by 2040$)$ of the total bioenergy consumption. Besides this, by 2040, the US will overtake China in terms of the total consumption of all types of bioenergy (Figure 7).

\section{Economic Aspects}

High growth rates of renewable energy production are largely dependent on substantial state support which, in a number of countries, is making renewable energy attractive even in cases where their economic output indices (without accounting for support mechanisms, taxation, etc.) are more than $50 \%$ worse than those of fossil fuels.

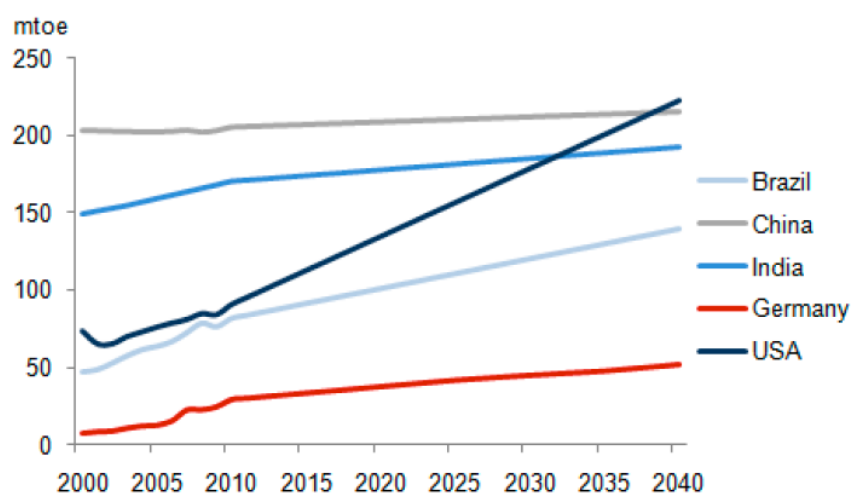

Figure 7: Dynamics of energy consumption in selected regions.

Source: [10].

A high degree of the dependence on the government support makes RES vulnerable in times of economic slowdown, when the economy will not provide the required level of support. Despite the improvement of technologies enabling the reduction of costs will help the development of renewable energy use; many of the renewable energy technologies will have to require government support for the next decades.

The competitive level of renewable energy sources in the electric power sector can be compared with conventional technologies in terms of the levelised costs of electricity (LCOE), which takes into account 


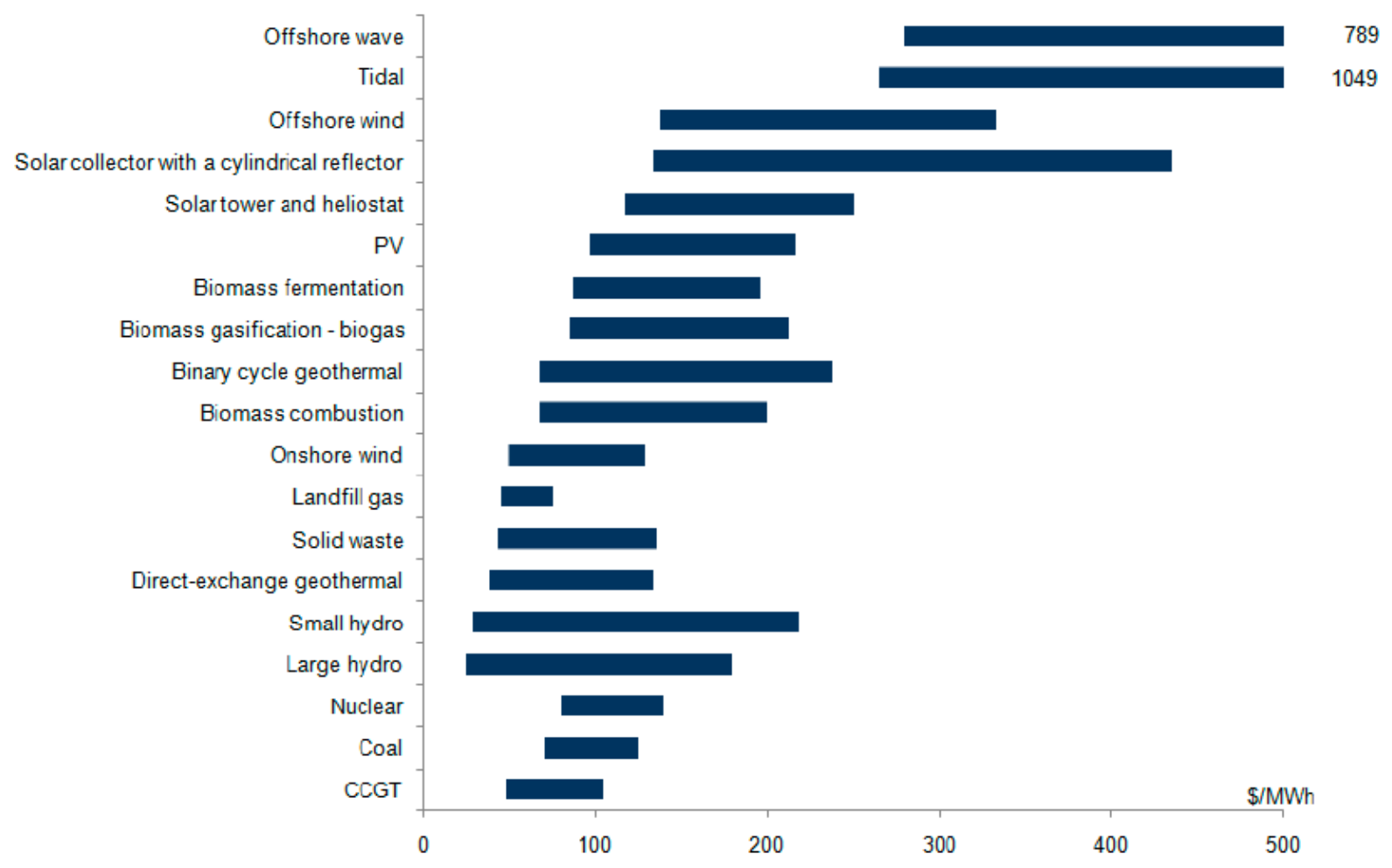

Figure 8: Global Levelised Cost of Electricity Ranges for Developed Markets.

Source: [10].

capital costs, fixed and variable operating costs, tax rates, the availability and effectiveness of the technology [9]. The most competitive renewable energy technologies are large and small hydro plants (about $\$ 30$ per MWh), which LCOE, in some cases, may be even lower than for nuclear, coal and gas power plants (Figure 8). Some geothermal plants may be economically close to hydro plants, but their use is limited to the regions where these (geothermal) resources are available. Among the biotechnologies, the most attractive one, in terms of this indicator, is municipal solid waste and landfill gas (starts from \$45 per $\mathrm{MWh}$ ). Onshore wind turbines, being already a well-developed and widespread technology, in fact match the LCOE range for traditional energy resources (\$50 $-\$ 130$ per MWh).

Over the forecast period, the global investments in new electric power plants and infrastructure are estimated at $\$ 19-\$ 20$ trln (2010). 32\% (about $\$ 6$ trln) of the total investment will be spent on the renewable energy development, $14 \%$ of which will be invested in the US and 22\% - in China (Figure 9).

In assessing the economic efficiency of renewable energy production, it is important to take regional peculiarities into account. Such features as: natural climatic conditions (intensity of solar radiation, wind speed, soil composition, etc.), the cost of labour and materials, the possibility of attracting investment, together with other factors, lead to a range of indicators for the attractiveness of different technologies (Figure 10). The greatest variation is observed in the production of electricity from solar energy, which is mainly determined by the country's geographical position.

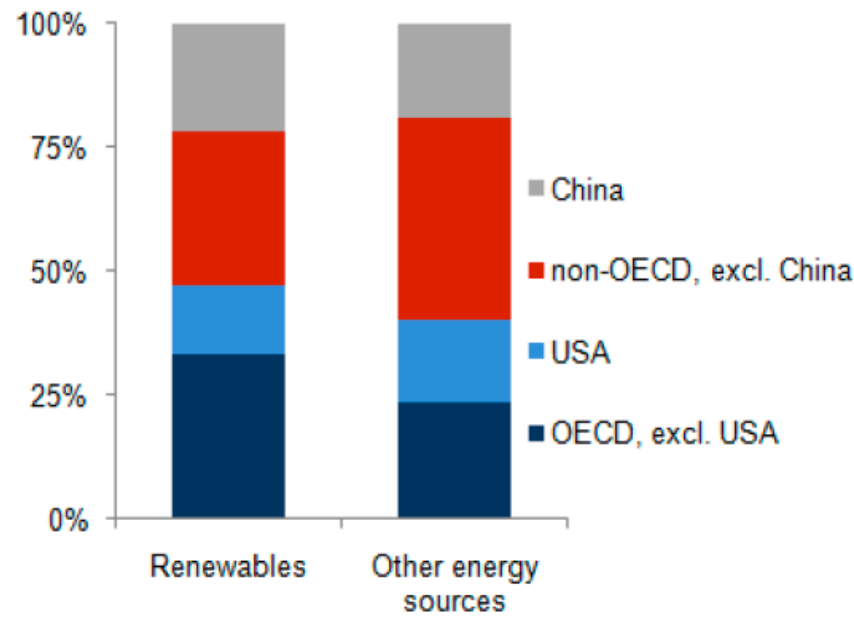

Figure 9: Regional Structure of Investments in the Construction of New Power Plants Utilizing Renewable and Other Energy Sources.

Source: [10]. 


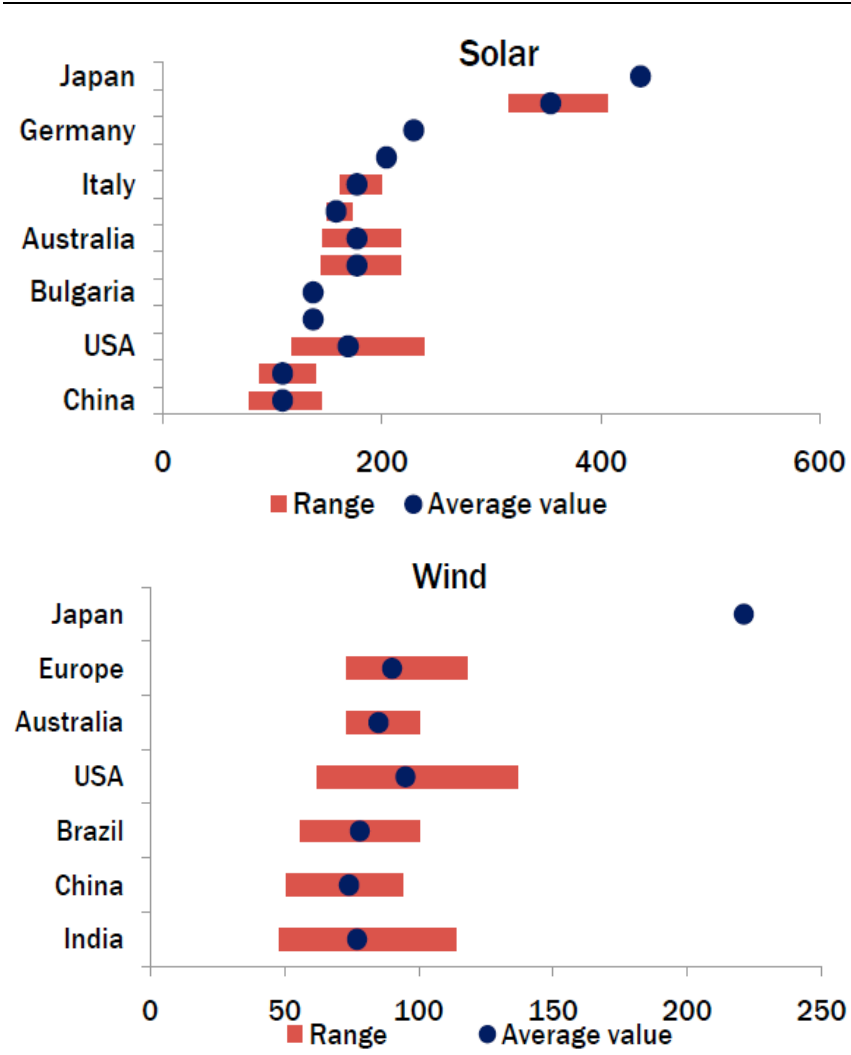

Figure 10: Levelised cost of electricity production based on solar and wind power plants on land.

Source: [2].

The rapid growth in the use of new forms of renewable energy in electricity generation poses additional problems to the whole energy sector because of the need for backup and storage methods to ensure the flexible operation of the energy system. In addition to the day-to-day variations in generation of electricity at facilities powered by renewables, a seasonal element must also be taken into account; this is reflected in the different intensities of solar radiation and wind strength at different times of the year. Because of this, monthly average capacity utilization may vary by a large factor. In fact, it results in an additional hidden increase in investment for the energy sector, which is often overlooked when comparisons are made directly with the cost of electricity production from a variety of sources.

In the period to 2040 many types of renewables will continue to require such support, despite anticipated technological improvements.

\section{CONCLUSIONS AND DISCUSSION}

The fuel mixes of different countries and regions will continue to differ remarkably throughout the forecast period. The demand for oil and coal in the OECD countries will decline, while the consumption of gas and renewables will increase. Non-OECD Asia will increase consumption of all fuels, primarily coal. The Middle East will significantly increase its consumption of hydrocarbons, especially gas. Africa will show the greatest increase in the use of bioenergy. Notably, electricity generation is the sector in which the main competition between all fuel types takes place in all regions, and this competition will only increase.

Changes in the fuel mix have a logical character. The crisis of 2008-10 marked the beginning of the fourth stage of global energy development, characterized by the increase of prices, diversification of fuel mixes, and even more restrained growth of energy consumption. The structure of global energy consumption will become more balanced. Instead of one type of fuel dominating in the mix (which has been the case for the entire recorded history of human energy usage) an evening out of fossil fuels is forecast by 2040 (oil - 26\%; gas - 24\%; coal - 26\%) and nonfossil fuels $(24 \%)$; this bears witness to the development of inter-fuel competition and improvement in the sustainability of supply.

Overall, RES are becoming more competitive and therefore will be used on an increasingly wide scale not only in the OECD countries, but also in the whole world. At the same time, due to the fact that RES start their take-off from a modest basis, they will only have a limited influence on the shares of hydrocarbons in the energy mix. It is still important however to assess the degree to which RES can influence the energy mix.

\section{REFERENCES}

[1] World Energy Outlook. Chapter 6. Renewable Energy Oulook: Basking in the Sun? Paris: OECD/IEA 2013; 197229.

[2] Makarov AA, Grigoriev LM, Eds. Global and Russian Energy Outlook up to 2040. Moscow: ERIRAS 2014.

[3] Annual Energy Outlook 2013 with Projections to 2040. Washington, D.C.: US Energy Information Administration 2013.

[4] BP Energy Outlook 2035. [cited 2014 October 20]: Available from: $\quad$ http://www.bp.com/en/global/corporate/aboutbp/energy-economics/energy-outlook/energy-outlookdownloads.html.

[5] ExxonMobil. The Outlook for Energy: A View to 2040. [cited 2014 Oct 20]: Available from: http://corporate.exxonmobil. com/en/energy/energy-outlook/download-the-report-andpresentation/download-the-outlook-for-energy-report.

[6] Makarov AA, Ed. SCANER: Super Complex For Active Navigation in Energy Research. Moscow: ERIRAS 2011.

[7] International Monetary Fund. World Economic Outlook 2013. [cited 2014 Jul 18]: Available from: http://www.imf.org/ external/pubs/ft/weo/2013/01/index.htm 
[8] Population Division of the Department of Economic and Social Affairs, United Nations. World Population Prospects: 2012 Revision. June 2013. [cited 2014 Jul 18]: Available from: http://esa.un.org/wpp/
[9]

Bloomberg New Energy Finance. World Survey of Energy Technologies. 2012.

[10] Makarov AA, Grigoriev LM, Eds. Global and Russian Energy Outlook up to 2040. Moscow: ERIRAS 2013.

Received on 28-07-2014

DOI: http://dx.doi.org/10.6000/1929-6002.2014.03.04.5

(C) 2014 Galkina et al.; Licensee Lifescience Global.

This is an open access article licensed under the terms of the Creative Commons Attribution Non-Commercial License (http://creativecommons.org/licenses/by-nc/3.0/) which permits unrestricted, non-commercial use, distribution and reproduction in any medium, provided the work is properly cited. 